\title{
Assessment of On-farm Diversity Status and Farmer's Perception for Landraces Crops at Eastern Hararghe, Ethiopia
}

\author{
Chala Tamiru*, Tahir Abdela \\ Ethiopian Biodiversity Institute, Harar Biodiversity Centre, Harar, Ethiopia \\ Email address: \\ chaliya2014@gmail.com (C. Tamiru), tahirbdela34@gmail.com (T. Abdela) \\ ${ }^{*}$ Corresponding author
}

To cite this article:

Chala Tamiru, Tahir Abdela. Assessment of On-farm Diversity Status and Farmer's Perception for Landraces Crops at Eastern Hararghe, Ethiopia. Agriculture, Forestry and Fisheries. Vol. 10, No. 4, 2021, pp. 152-159. doi: 10.11648/j.aff.20211004.15

Received: June 11, 2021; Accepted: July 9, 2021; Published: July 15, 2021

\begin{abstract}
Ethiopia is centre of origin for crops such as sorghum, teff, coffee and enset and centre of diversity for many other crops (wheat, barley, Ethiopian mustard, chickpea lentils and finger millet). Similarly eastern Hararghe has diverse agro-ecology that shows diversity of many crops. So, a total of 15 land race crop species was identified with 36 accessions from 2 regions and 6woreda. From total 15 farmer variety of crop and 36 accession, sorghum are the highest accession and more cultivated in study area and it account 13 accession (36.1\%). From the total survey of woreda, Qarsa is the most diverse crop species since it has a wide agro-ecology and holds ten crop species $66.7 \%$ of total crop in study area. Jarso is the second crop diversity in study area it hold eight crop species (53.3\%). Sofi and Babile are the third crop diversity in study area it hold four crop species each (26.7\%). Expansion of chat and replacement of modern variety in study area are the most loss of farmer variety it holds $45 \%$ and $40 \%$ respectively. Six farmer crop species in study area like Badu Oanyii, Shakoo, Bukuri, Minjar, Barley and wheat are threatened in study area due to Replacement of modern variety, no good test and low value market, birds' interest, lack of fodder, weed and drought. Therefore, creating awareness for local farmers on how to manage the crop effectively (sowing, weeding, harvesting and storing) and conserve the landrace variety. More agricultural research should be conducted on the characters and requirement of the crops for various regions and environments to conserve landrace variety.
\end{abstract}

Keywords: Crop Diversity, Ethiopia, Hararghe, Landrace, On-farm Diversity, Farmers' Perception

\section{Introduction}

Ethiopia is recognized as an important source of the public goods associated with crop genetic diversity conservation. Ethiopia is considered as one of the richest genetic resource centers in the world. According to Mekbib [17], Ethiopian is characterized by diverse agro-ecology, which account for the enormous diversity of biological resources that exist in the country. For many crop species, Ethiopia is considered to be the centre of origin and diversity for instance; tef (Eragrostis tef), coffee (Coffea arabica), noug (Guizotia abyssinica), gesho (Rhamnus prinoides), enset (Ensete ventricosum), Yam (Dioscorea abyssinica) and chat (Catha edulis). Those crops are distributed over a wide range of agro-ecological areas in the country $[22,23]$. Diverse genetic resources are used and managed in various ways by farmers. The number of crop accessions of Ethiopian origin that have been introduced to various international and foreign national crop improvement programs and seed companies is enormous which accounts more than 1800 for wheat and more than 4500 for sorghum, around 2500 for barley and more than 900, large numbers are also reported for chickpea, lentil and finger millet [12].

The indigenous plant species, their wild relatives and weedy species which form the basis of Ethiopia's crop genetic resources are highly prized for their potential value as sources of important variations for crop improvement programs [19]. Crop genetic resources comprise the building blocks of modern agricultural production to give food to the growing of people currently we face [18]. They form as the raw material from which new varieties have been 
systematically bred to meet the growing need for more food [7]. In many cases, small-scale farmers mainly depend on local genetic diversity to ensure sustainable production utilization and meet their livelihood needs. Loss of genetic choices as reflected by loss of traditional crop varieties reduces farmers' capacities to survive with changes in pest and disease infection that leads to yield instability and loss [21]. According to Ceccarelli and Grando [3], landraces or local varieties have been found to have higher stability in marginal environments, and thus their cultivation may contribute to farm level resilience in the face of production shocks.

Genetic erosion refers to failure of genetic irregularity over space and time. In real sense, it represents either the loss of entire populations or the loss or change in frequency of specific alleles particularly, rare alleles or allele combinations present within a population or in a given species as a whole. It commonly occurs in local (indigenous) species and often caused by human-driven or -related activities. Additionally, limited attention has been given to assess the diversity and conservation of indigenous crop genetic resources. As a result, some of indigenous crop genetic resources in Ethiopia are endangered, even they may be lost before they characterize and conserve [18].

Accordingly, in order to put off the problem and for mitigating production bottlenecks and supporting food security especially in resource-poor countries, in situ conservation of genetic resources especially in areas of domestication or origin, where diversity of genetic resources is intense, is very important [8]. Similarly, maintaining onfarm genetic diversity and farmers' indigenous knowledge along with their behavioral practices of keeping landraces of ancestral crop populations are also another evenly important strategy for conserving crop species [16]. Keeping the landraces and/or reversing their loss is absolutely essential since they are potential sources of materials for modern and stable selection breeding and for developing lines that are resistant to biotic and abiotic stresses.

Attempts made so far to conserve the crop is very less except few explorations and rescue collections targeting maintenance even though, Ethiopia is the countries of being the world's rich biodiversity center and harboring a variety of distinct food crops. On-farm genetic resource conservation and research activities targeting improvement of indigenous crops received less consideration in several countries still now. In recent days, the country is under severing threat of loss in genetic diversity and most of the indigenous food crops are at threat of total destruction [15]. According to [10], landraces are those crops regardless of their valuable and distinctive agronomic traits. Up to date, their cultivation is declining from time to time and only practiced by smallholder farmers for survival use. The present study has, therefore, been initiated with the following objectives:

To document diversity of crop landrace and assessing its current status in eastern Hararghe of Ethiopia.

To assess perception of farmers on loss of land race and threaten farmers' variety in eastern Hararghe.

\section{Materials and Methods}

\subsection{Description of the Study Area}

The study zone is located in the eastern part of Oromia National Regional State. Harar is capita city of eastern Hararghe zone. It is located at a distance of $526 \mathrm{Km}$ from Addis Ababa. The zone has the total area of 24,247.66 km and is geographically located between 70321-90441 North latitude and 410101-430161 East longitudes [4]. The physiographic condition of the zone is characterized by plateaus, rugged dissected mountains, deep valleys, gorges and plains. There are various prominent and Peaks Mountains in the zone like Kundudo and Gara Mullata mountain chain are the major ones. The zone is bordered by West Hararghe zone in the west, Bale zone in the south, Somali National Regional State in the east and south-east, and Dire Dawa Administrative Council in the north. Harari Regional State is encircled by the East Hararghe zone. Harari is one of nine national regional states in Ethiopia having nineteen kebeles (lower administrative level).

Geographically, the area is located between 42003' 30', 420.16' 24 '' $\mathrm{E}$ and $90.11-90,24^{\circ} \mathrm{E} \mathrm{N}$ with an altitude ranging from $1300-1600$ m.a.s.l. The mean annual rainfall the area is $636.7 \mathrm{~mm}$ and the mean annual temperature is $19^{\circ} \mathrm{C}$. Generally the region has a total area of $334 \mathrm{~km}^{2}$ [11]. Agro-ecologically of eastern Hararghe zone is divided into highland, midland and lowland areas that cover $11.4 \%, 26.4 \%$ and $62.2 \%$ of the total area of the zone, respectively. It receives annual rainfall of 1,200 to $2000 \mathrm{~mm}$. The average temperature varies from $100^{\circ} \mathrm{C}$ to $150^{\circ} \mathrm{C}$. The midland agro-ecological zone has an altitude of 1,500-2,300 m.a.s.l. with annual rainfall ranging from 600 to $2000 \mathrm{~mm}$. Low agro-ecological zone, which covers a total area of 14,076 ha, is found in the south eastern and northern parts of the zone bordering Bale zone, Somali Regional State and Dire Dawa Administrative Council.

As elsewhere in the country, agriculture is the dominant economic activity and the base of livelihood of the majority of the residents of both study area similar. In the farming system, there are three production systems in East Hararghe zone. These are the mixed farming (crop and livestock production), the pastoral and the transitional (agro- pastoral farming). The mixed farming and the pastoral areas account for about 40 and 50\% respectively [4]. The agro-pastoral system is practiced in lowland areas of East Hararghe zone which accounts for $10 \%$.

\subsection{Methods of Data Collection and Research Design}

Selected districts and kebeles were identified after a rapid first round informal survey and discussions with the Zone and districts agricultural bureau experts. Both primary and secondary sources were used for gathering information. At different farm fields, a questioner, household interview, and focus group discussions (FGD) using key informants and personal observations were used for collecting data with farmers who cultivate farmer variety crop on farm land. Questionnaire was used with the intention of setting 
information from a wide range of sources (respondents) regarding the indigenous knowledge and practices involved in crops landraces farming, management practices, conservation and utilizations in the study areas. It was written in English and translated into local languages such as 'Afan Oromo' and 'Amharic' and distributed to the selected 160 household heads. The household heads were purposively selected based on the preliminary survey and information documented from district agricultural offices. Additionally, in order to assure good coverage of the required diversity in indigenous knowledge, all the compulsory age groups and sexes including leader women household were purposely involved in.

Semi structured questions that address matters concerning the cereal crops landraces currently or used to be cultivated, extents of their production challenges, and major utilizations were presented. The 10 key informants from each kebele were carefully selected during harvesting cropping season in 2020 from the household heads of both sexes and different age groups involved in the questionnaire method based. Focal group discussions were carried out with growing elders of selected crop species to complement the information obtained from individual farmers and to minimize missing data. The key informants involved were well recognized elder farmers aged 50 or more and spent their entire lives in the localities and were engaged in landrace crops farming and seed selection. Open group discussions regarding the reasons why crop landraces are left marginalized, main factors for the current decline in production of the landraces, and their general views regarding the benefits of the landraces were presented. After thorough discussion, consolidate ideas were noted at the end.

Agricultural extension experts, development agents (DAs) at all the selected districts and Peasant Association levels, experienced researchers at Ethiopian biodiversity institute mandated for research on cereal crops were check with whether the landraces identified by farmers were really landraces or improved varieties. Furthermore, secondary data from the Ethiopian Biodiversity Institute (EBI) were used to validate the landraces and screen the improved and exotic varieties released through the formal system.

\subsection{Data Analysis}

The collected qualitative and quantitative data were mostly analyzed and summarized by table. The data on level of land race threat and local name was analyzed by descriptive statics such as, Table, graph and percentage by using excel Microsoft.

\section{Result and Discussion}

\subsection{Respondent Sociodemographic Characteristics}

In the present study, the marital status from total of 120 respondents were interviewed from the six districts (20 from each) of which the majority were male respondents 100 $(83.33 \%)$ and the rest $20(16.67 \%)$ were female respondents (Figure 1). Males are more involved in agricultural practices as compared to females in the study area. Active participation of women are dominant in other activities like selling and buying chat because income generated from crop production is too low as compared to chat. Other reality that pushes female from agricultural crop activities toward production of chat is that they are yet under cultural burden that prohibited their participation in farmlands.

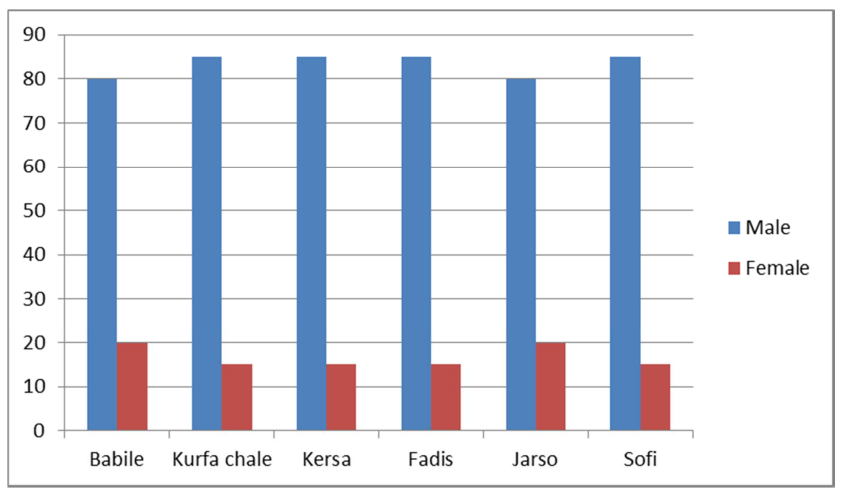

Figure 1. Marital status of respondent in the study area.

Regarding to educational status larger proportion of the respondents $60(50 \%)$ had were uneducated and $36(30 \%)$ respondents were primary school education (figure 2). Eighteen (18) (15\%) respondents and small number of respondents $6(5 \%)$ were secondary educated and completed 12 grade respectively. Even though large number of respondent in all study area were illiterate (they didn't write and read) and primary educated and less than that,they have been involved in different crop landrace selection, conservation, and maintenance processes due to they have indigenous knowledge.

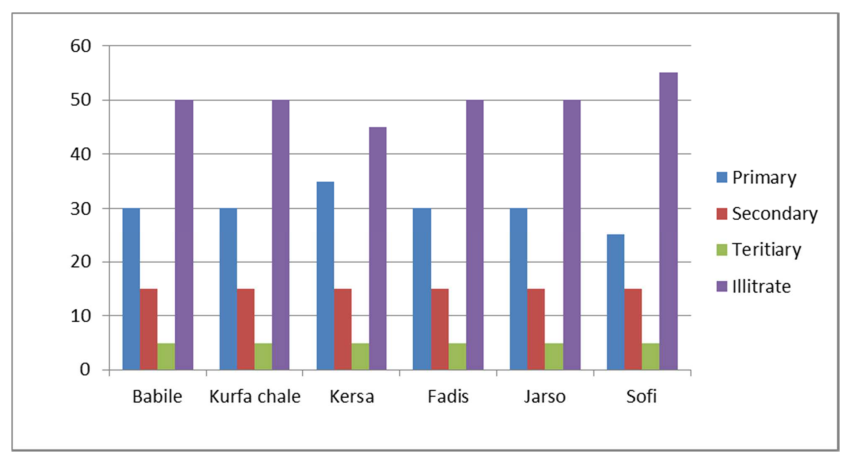

Figure 2. Educational status of recruited respondents in the study area.

From the recruited 120 respondents, highest age group were between $36-50$ (32.50\%) followed by $16-35$ (27.5\%) (Figure 3). Respondent age between 0-15 accounts 20.83\% followed by above 50 years old were $19.17 \%$. 


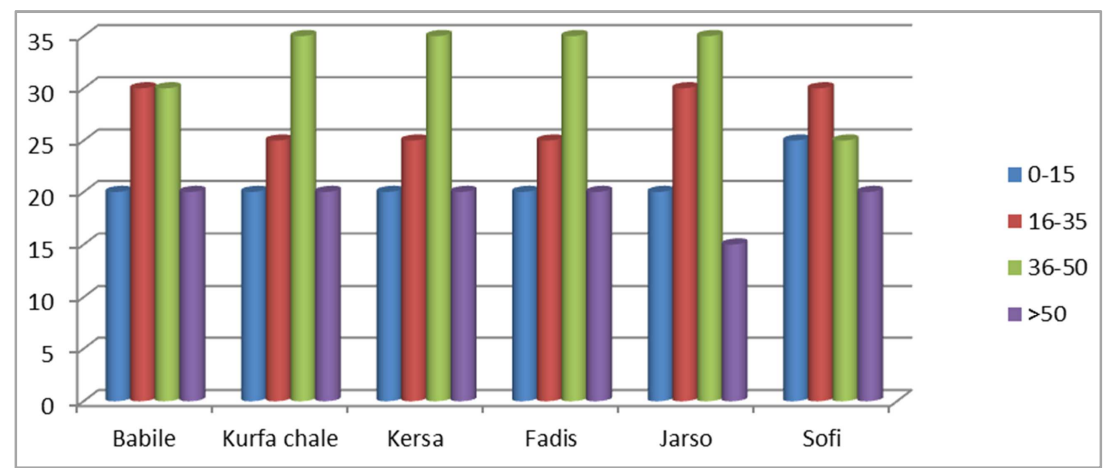

Figure 3. Respondents age of Respondents in the study area.

\subsection{On-farm Conservation of Landrace}

According to this finding, famers in the study area follows principles of on-farm conservation which involves farmers' continued cultivation and management of a diverse set of crop populations in the agro ecosystem where the crop evolved or in secondary centres of diversity. It depends on farmers' active participation based on their reasons and incentives for maintaining diversity [2]. Crop genetic diversity is unequally distributed around the world and is concentrated in centres of diversity that often coincide with centres of crop domestication [9]. Greater numbers of respondents were agreed that farmers are able to keep landraces adapted to their growing conditions and sociocultural preferences through farming practices (time of planting, thinning, and seed selection). The objective of onfarm conservation is therefore to maintain crop evolution in farmers' fields, farms and landscapes. The reason to maintain evolutionary processes in crops is 'to generate new potentially useful genetic variation, which in turn contributes to maintain the capacity of agricultural and food systems to adapt to change, particularly if it is unpredictable' [1]. In the same way, all number of respondents raised ideas that keep their landrace crops as it is not to become extinct. Additionally they said that government and non government should be doing on it in order to keep the life span of this landrace crops. In line with this idea [6] proved that what economists call option values, which are to do with the idea that maintaining diversity keeps our options open to benefit from unanticipated future uses of biodiversity. A crucial aspect of on-farm conservation is the seed systems that are associated with the maintenance and management of landraces in centers of crop diversity [20]. A seed system refers to the interrelated set of participants, rules, interactions and infrastructure by which farmers obtain seed or planting material through time and space. Historically seed systems have been in the hands of farmers and communities, and are usually referred to as local, informal or traditional seed systems.

\subsection{Identified Status of Farm Land Race}

According to this survey result, 33 accessions of land race farmers' variety were identified in study area that holds 15 crop species. From the total of 33 accession sorghum are most high accession holds 9 (27.27\%) and highly cultivated in study area. Maize and bean are the second holds high accession its 3 in number $(9.0 \%)$. Hulbata, misira (Lentil), Ground nut, pea and barley are the $3^{\text {rd }}$ holds high accession it two accessions $(6.0 \%)$. When the rest of crops hold one accession each $(3.0 \%)$ (Table 1). Landraces is an important genetic resource that has been included in international treaties and national decrees that protect and enhance their use in their local environments. However, legislation is needed to make it possible to market landraces as diversified genetic materials. National and international legislation was designed primarily to protect trade and return royalty income to expensively-funded plant breeding programs; as landraces become more attractive to use in local food production and sustainability, legislation changes are needed to facilitate this trend and to promote exportation and exchange of landrace diversity and encourage their use [13, 14].

Table 1. Identified land race crop, their local name, accession and collected place in study area.

\begin{tabular}{llll}
\hline Crops species & Local name & Accession & Collected place \\
\hline & Afareee & 01 & Kurfa chalee \\
& Muyraa adii & 02 & Kurfa chalee \\
& Muyraa diima & Kurfa chalee \\
& Come & 03 & Kurfa chalee \\
& Shako & 04 & Sofi woreda \\
Diima & 05 & Sofi,babile & Sofi,babile \\
Badu qanyii & 06 & Dire tayarra \\
& faddish & 07 & Sofi,babile \\
& Dangaa & 08 & Sofi \\
& Dukkun & 09 & Fadis \\
& Wagaree & 010 & Fadis
\end{tabular}




\begin{tabular}{llll}
\hline Crops species & Local name & Accession & Collected place \\
\hline \multirow{4}{*}{ Maize } & Carcaroo & 013 & Fadis \\
& Bukuri & 014 & Jarsoo \\
Hulbata & Minjar & 015 & Jarsoo \\
poqollodimtuu/shoote & 016 & Jarsoo \\
pea & Hulbatanyataa (gurracha) & 017 & Jarsoo, Qarsaa, Kurfa \\
& Hulbata dhugan (adii) & 018 & Jarsoo, Qarsaa \\
Bean & Baqeelagudda & 019 & Jarsoo, Qarsaa \\
& Baquelaxiqaa & 020 & Jarsoo, Qarsaa \\
Cabbage fruit & Ashangoree & 021 & Babile, Qarsaa \\
Avain & Horgobee & 022 & Babile, Sofi \\
& shukrii & babile \\
& Midhanrafuu & 023 & Qarsaa, Babile \\
& Esoo & 024 & Jarsoo, Qarsaa \\
& Heexo & 025 & Jarsoo, Qarsaa \\
\multirow{2}{*}{ Ground nut } & Qonxar & 026 & Qarsaa, kurfa \\
& Misira & 027 & Jarsoo, Qarsaa, kurfaa chalee \\
sesame & Dangulee & 028 & Qarsaa \\
& Oldhalee & 029 & Sofi,babile \\
Barley & Sartuu & 030 & Sofi,babile \\
Wheat & White & 031 & Sofi,babile \\
\hline
\end{tabular}

From this survey result, indicated above (Table 1) and (Figure 4) below sorghum species were more dominant, high accession and more cultivated in study area. Ground nut, pea, sesame, barley, lentil and Hulbata are the $3^{\text {rd }}$ high accession and hold two accessions each in study area. Five of them such as avian, hexoo, qonxar, dangule and cabbage were cultivated equally in study area. They were hold only one accession and avain, dangule and qonxar cultivated only one place in study area. This survey showed that avain, maize, qonxar and dangule were threated farmers variety in study area and need priority conservation.

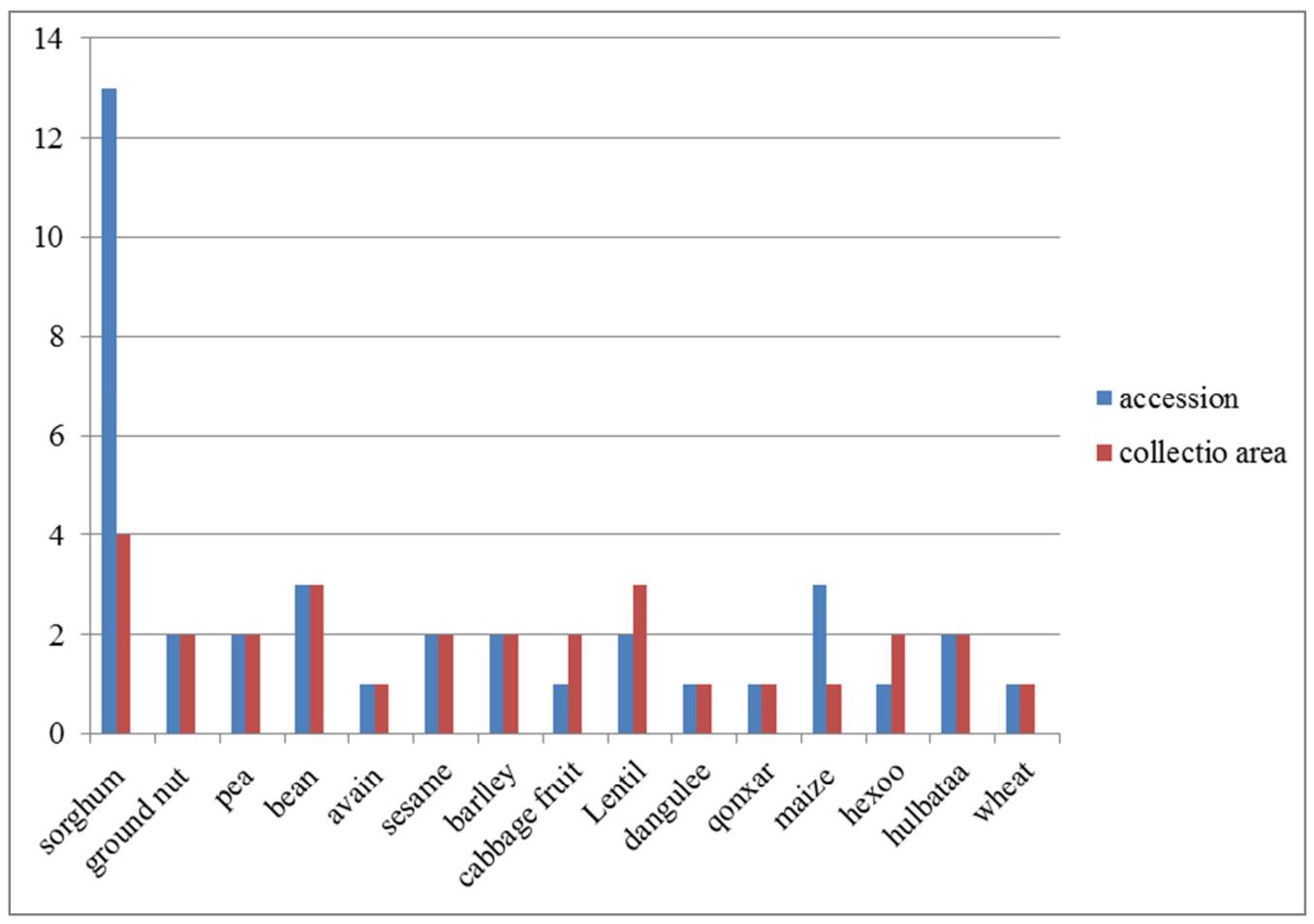

Figure 4. Land race accession and collection area.

From the recruited 120 respondents and conducted research survey showed that more crop diversity were recorded in Qarsa woreda followed by Jarso which account $10(66.7 \%)$ and $8(53.3 \%)$ crop species respectively (Figure
5). In the same way Babile and Sofi woreda were the $3^{\text {rd }}$ crop diversity in study area and both were hold 4 crop species (26.7\%). Dirre and Fadis woreda were the least crop diversity in study area it account only one crop species (6.7\%). 


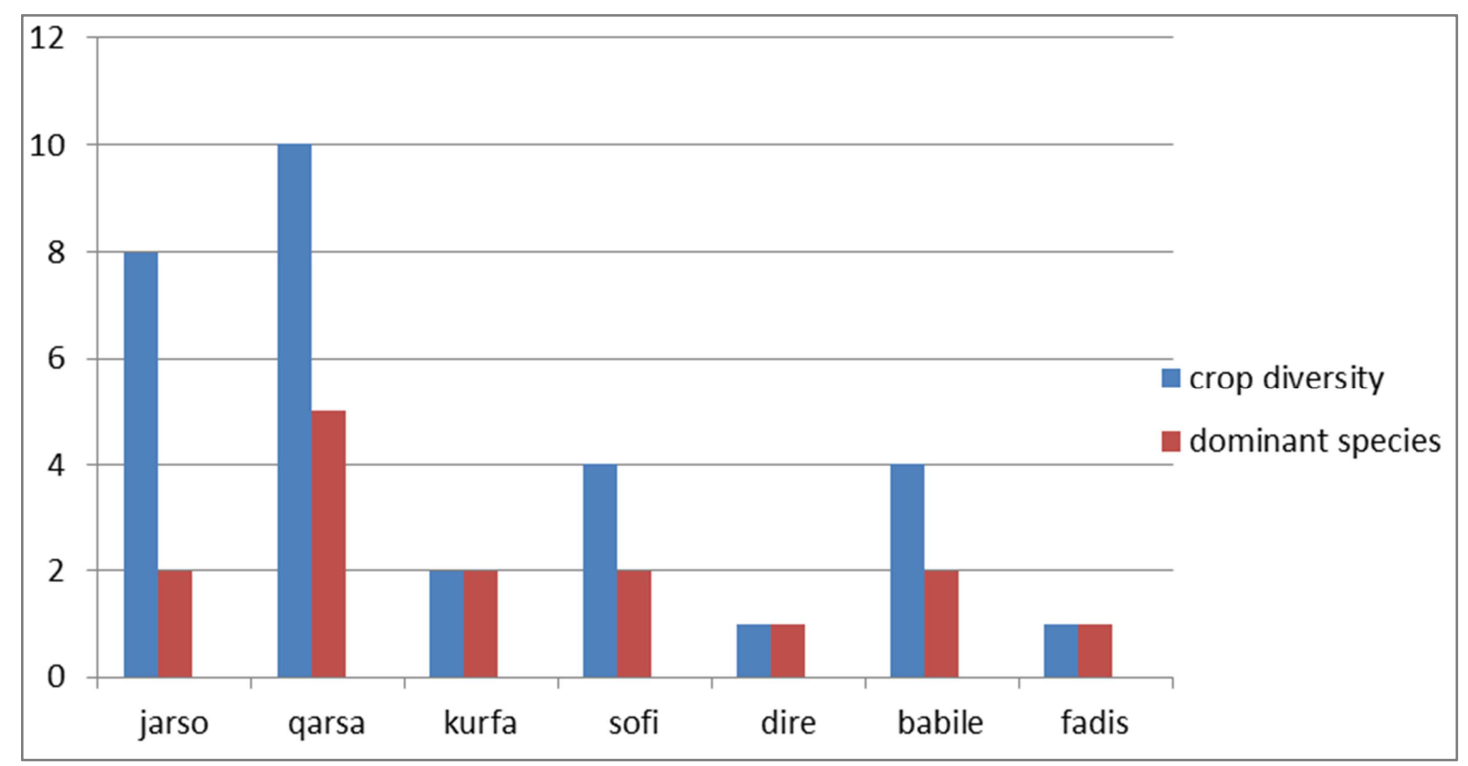

Figure 5. Collection area and diversity of farmers' crops.

\subsection{Farmers' Perceptions on Replacement and Loss of Traditional Crop Varieties}

Farmers in the study districts purposely maintain landraces to address various needs. The main traits farmers use to prefer a given variety over the other were maturity, yield potential, suitability for animal feed, grain size, grain color, tillering capacity, market demand, condition of the soil and product volume. This showed that their rich knowledge and behavioral practices in cereal crop and others landrace production. Similar to current result [5], the selection criteria for landraces of barley reflect adaptations to changing farming conditions, and responses to the socio-economic and cultural factors that shape farmers priorities. In the same way study made on enset showed that the biggest uses of landraces are for kocho, bulla, amicho, fiber and medicine [24]. A study made on wheat indicated a wide range of variations among landraces for the traits studied which help farmers with an opportunity to make a choice of genotypes that fit their purpose [25].

This survey study also showed that and large numbers of farmers had the similar idea on the replacement of modern variety was the most farmer variety loss $(45 \%)$ in study area. Other factor contribution to lose of landrace was expansion of chat in eastern Hararghe area (40\%). The third and fourth possible factors that leads to loss of landrace variety in the study area were repeated drought and weed disease followed by less production of land race variety in study area (Farmers respond). Most of farmers in the study area said that it is become harder to find traditional varieties of crops due to their replacement by the new ones as the traditional varieties are becoming less productive, no longer tolerant to drought, susceptible to diseases and incompatible with the type of soil farmers are dealing with. In line with current result, farmers understood the general pattern of yield deterioration in their own varieties and make a replacement decision accordingly.

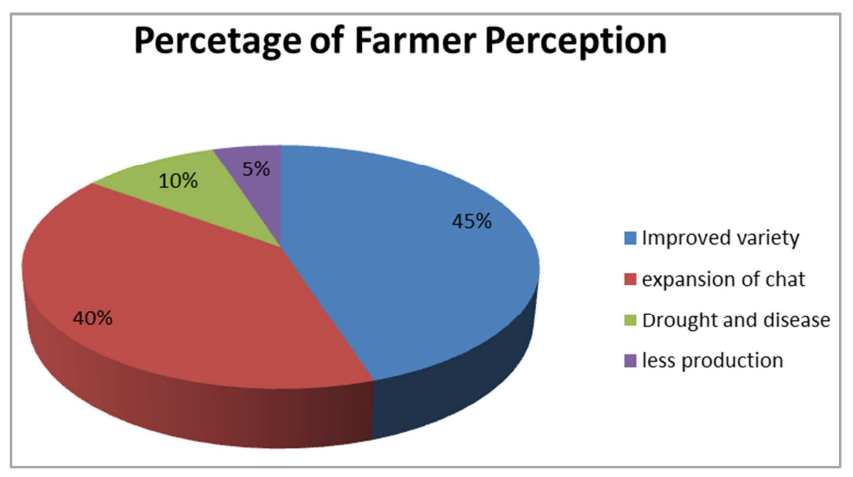

Figure 6. Percentage of farmer perception on farmer variety loss.

Respondent in the study were different outlook and perception in time of sowing, maturity and harvesting (Table 2). The accession of sorghum shako, dangaa and dukkun and accession of maize minjar have late maturity in study area according to match with rain period of the area. However, shako and minjar have high production. Since, it is late maturity not interested by people according with rain fall period. Inversely, other accession like baduqanyi, bukri and shoote have short maturity but their also low production and due to other factor like highly effect of striga, high bird interest are major problem as farmer replace other new variety.

\subsection{Threatened Farmer Crop Species, Season of Sowing and Harvesting}

Data recorded from survey result showed that four crop species in study area were threatened due to different factor (Table 3). Badu qanyi (Local name) is one accession of sorghum now it was lost in study area due to some possible reason like high bird interest, lack of fodder. Since, it is short and thin steam high affected by striga and easily susceptible to drought. Dangaa is also one of accession of sorghum now it was less cultivated in study area due to no good test of food 
and high bird interest. Shako and dukkun were also sorghum accession now less cultivated in study area due to take long maturity and no good test and low market value respectively. Minjar, Bukuri and Shoote were maize accession of farmer variety currently lost long time for maturity and replaced by modern variety and high weed affect, less production and replacement of modern variety and high weed affect, replacement of modern variety and drought respectively in the study area. Doloo and Rogafree were wheat and barley accession and both were lost by replacement of modern variety.

Table 2. Season of sowing and harvesting time of selected crop species.

\begin{tabular}{|c|c|c|c|c|c|c|}
\hline No & Crop species & accession & Sowing time & Harvesting time & Output production & Rain period \\
\hline \multirow{5}{*}{1} & \multirow{4}{*}{ Sorghum } & Shakoo & May & December & High & May -august \\
\hline & & Dangaa & May & December & medium & May -august \\
\hline & & Badu qanyi & June & October & Low production & May -august \\
\hline & & dukkun & May & December & Medium & May -august \\
\hline & \multirow{3}{*}{ Maize } & Minjar & May & October & High production & May -august \\
\hline \multirow[t]{2}{*}{2} & & Bukuri & June & September & Low production & May -august \\
\hline & & shoote & June & September & Low production & May-august \\
\hline 4 & Barley & Rogafree & 15June & September & High & May-august \\
\hline
\end{tabular}

Table 3. Threatened farmer crop and reason for accession lost.

\begin{tabular}{ll}
\hline Threatened accession & Reason of loss \\
\hline Badu qanyi/butanne & Birds interest, lack of fodder, weed and drought \\
Dangaa & No good test food and high bird interest \\
Shako & It take long maturity \\
Dukkun & No good test and low value market \\
Minjar & It take long maturity and replace by modern variety \\
Bukuri & High weed affect, less production and replacement of modern variety \\
Shoote/diimtu & High weed affect, replacement of modern variety and drought \\
doloo t & Replacement of modern variety \\
Rogafree & Replacement of modern variety \\
\hline
\end{tabular}

\section{Conclusion and Recommendation}

Ethiopia is considered as centre of origin for crops such as: sorghum, teff, coffee and enset, and is centre of diversity for many others such as: wheat, barley, Ethiopian mustard, chickpea lentils and finger millet. Similarly eastern Hararghe which has diverse agro-ecology has different indigenous crop species. A total of 15 land race crop species were identified with 36 accessions from 2 regions and 6 woreda. From total 15 farmer variety of crop and 36 accession, sorghum are the highest accession and more cultivated in study area it account 13 accession (36.1\%). Maize and bean are the second high accession in study area it account three accession each $(8.3 \%)$. Lentil, ground nut, hulbat, pea, barley and sesame are the third high accession it account two accession each (5.6\%). The remaining crop species like qontor, dangule, wheat, cabbage fruit and avain are the least hold accession it account one each $(2.8 \%)$. From the total surveyed of woreda, Qarsa is the most diverse crop species since it wide agro-ecology it hold ten crop species $66.7 \%$ of total crop in study area. Jarso is the second crop diversity in study area it hold eight crop species (53.3\%). Sofi and babile are the third crop diversity in study area it hold four crop species each $(26.7 \%)$. Kurfa chale woreda is followed Sofi and Babile it hold two crop species (13.3\%). Dire and Fadis is the least crop diversity in study was it mostly cultivates only one species $(6.7 \%)$. Expansion of chat and replacement of modern variety in study area were the most loss of farmer variety it holds $45 \%$ and $40 \%$ respectively. Repeated drought and weed disease and less production of land race variety in study area were $3^{\text {rd }}$ and $4^{\text {th }}$ the loss of farmer variety respectively. Six farmer crop species in study area like Badu Qanyii, Shakoo, Bukuri, Minjar, Barley and wheat were threatened in study area due to replacement of modern variety, no good test and low value market, bird's interest, lack of fodder, weed and drought. Therefore, the following recommendation is used for future conservation:

Continuous study of each crop diversity and genetic erosion, conservation of on -farm diversity, awareness creation on on-farm land race conservation, sustainable utilization and use of farmer variety should be enhanced.

Creating awareness for local farmers on how to manage the crop effectively (sowing, weeding, harvesting and storing) and conserve the landrace variety.

More agricultural research should be conducted on the characters and requirement of the crop for various regions and environments to conserve landrace variety.

\section{References}

[1] Bellon, M. R. (2009) Do we need crop landraces for the future? Realizing the global option value of in situ conservation. In: Kontoleon, A., Pascual, U. and Smale, M. (eds) Agrobiodiversity and Economic Development. Routledge, London and New York, pp. 51-61.

[2] Bellon, M. R., Pham, J. L. and Jackson, M. T. (1997) Genetic conservation: a role for rice farmers. In: Maxted, N., Ford-Lloyd, B. V. and Hawkes, J. G. (eds) Plant Conservation: the In Situ Approach. Chapman and Hall, London, pp. 263-289. 
[3] Ceccarelli, S and S. Grando 2002 Plant Breeding with Farmers Requires Testing the Assumptions of Conventional Plant Breeding: Lessons from the ICARDA Barley Program in D. A. Cleveland and D. Solerieds. Farmers, Scientists and Plant Breeding Integrating Knowledge and Practice CABI International NY

[4] EHFEDO, 2012. East Haraghe Zone Finance and Economic Development Office. Annual report of 2012.

[5] Eticha F, Berghofer E, Grausgruber H (2008). Characterization and Utilization of barley (Hordeum vulgare L.) landraces in the highlands of West Shewa, Ethiopia. Plant Genetic Resources 7: 154-162.

[6] Faith, D. P., Magallon, S, Hendry, A. P., Conti, E., Yahara, T. et al. (2010) Ecosystem services: an evolutionary perspective on the links between biodiversity and human well-being. Current Opinion in Environmental Sustainability 2, 1-9.

[7] FAO, 2004a. Global Information and Early Warning System on Food and Agriculture World Food Programme. Special report on FAO/WFP crop and food supply assessment in Ethiopia.

[8] FAO, "Global plan of action on the conservation and sustainable utilization of plant genetic resources for food and agriculture," in The International Technical Conference on Plant Genetic Resources, p. 63, Leipzig, Germany, 1996.

[9] Gepts, P. (2006) Plant genetic resources conservation and utilization: the accomplishments and future of a societal insurance policy. Crop Science 46, 2278-2292.

[10] H. R. Harlan and M. L. Martini, Problems and Results of Barley Breeding, USDA Yearbook of Agriculture, Washington DC, US Government Printing Office, 1936.

[11] Harar Biodiversity Center Over view of Socio Economic Data on Eastern Ethiopia Region Unpublished), Harar, Ethiopia, 2016.

[12] ICCPPGR/FAO (1997), FAO: Plant Genetic Resources, FAORome, Italy, http://web.icppgr.fao.org/.

[13] Jaradat, A. A. 1992a. Breeding potential of durum wheat landraces from Jordan II. Differential responses to drought. Hereditas 116: 305-309.

[14] Joshi, K. D. and J. R. Witcomb. 2003. The impact of participatory plant breeding (PPB) on landrace diversity: A case study of high- altitude rice in Nepal. Euphytica 134: 117125 .
[15] M. Girma, "Genetic erosion of barley in North Shewa Zone of Oromiya Region, Ethiopia," International Journal of Biodiversity and Conservation, vol. 6, no. 3, pp. 280-289, 2014.

[16] M. R. Bellon and J. E. Taylor, "Farmer soil taxonomy and technology adoption," Economic Development and CulturalChange, vol. 41, pp. 764-786, 1993.

[17] Mekbib, F. (2007). Intra-specific folk taxonomy in sorghum (Sorghum bicolor (L.) Moench) in Ethiopia: folk nomenclature, classification, and criteria. Journal of Ethnobiology and Ethno medicine. 3 (38): 1-18.

[18] Mulualem T. (2017). Genetic Diversity, Path Coefficient Analysis, Classification and Evaluation of Yams (Dioscorea spp.) in Southwest Ethiopia. PhD dissertation, Haramaya University, Ethiopia.

[19] Mulualem T. and Bekeko Z. (2014). Diversity and conservation of wild crop relatives for source of resistance to major biotic stress: Experiences in Ethiopia. Journal of Gene tic and Environmental Resources Conservation. 2 (3): 331348 .

[20] Pautasso, M., Aistara, G., Barnaud, A., Caillon, S., Coomes, O. et al. (2012) Seed exchange networks for agro biodiversity conservation. A review. Agronomy for Sustainable Development. doi: 10.1007/s13593-012-0089-6.

[21] Teshome, H. (2006). Local Crop Genetic Resource Utilization and Management in Gindeberet, West Central Ethiopia. MSc Thesis, Norwegian University of Life Sciences, Norway.

[22] Vavilov, N. I., (1977), The origin, variation, immunity, and breeding of cultivated plants. In: Selected writings of N. I. Vavilov, ChronicaBotanica, 13: 1-16.

[23] Worede, M. (1991). Crop genetic resources conservation and utilization: An Ethiopian perspective, science in Africa: Achievements and prospects. Proceedings of the symposium of the American association for advancement of science, Washington, DC, USA. 46p.

[24] Zerihun Y, Kassahun T, Awole Z, Guy B (2016). Exploiting indigenous knowledge of subsistence farmer"s for the management and conservation of Enset (Ensete ventricosum (Welw.) Cheesman) (musaceae family) diversity on-farm. Journal of Ethnobiology and Ethnomedicine 12 (1): 34.

[25] Zewdie B, Paul CS, Anthony JGG (2014). Assessment of onfarm diversity of wheat varieties and landraces; evidence from farmer"s fields in Ethiopia. African Journal of Agricultural Research 9: 2948-2963. 